\title{
Towards an inclusive pedagogy in South Africa
}

\author{
SIGAMONEY NAICKER \\ Western Cape University \\ South Africa
}

Very little has been done concerning mass education since it was introduced for working class children in developing and poor countries. Bowles and Gintis (1976) warned us that schools reproduce the status quo. When developed nations plan they plan for the middle class because the middle class are in the majority. Developing countries, following this model also plan for the middle class but the majority of children in developing countries are working class. This action further marginalises the working class. Whilst this paper is contradictory in suggesting a first world inclusive education model $\mathrm{I}$ am of the view that you cannot throw the baby out with the bathwater. There is enormous merit in following the inclusion model since it holds promise for working class children and vulnerable children who constitute the majority population in developing countries schooling systems. Developing countries should plan on the basis of the specificities of their contexts and continue to refine theories and models with a view to ensuring that more children graduate from school.

Working class children will struggle in the contemporary world because of the politicisation of education which results in a performative culture. With the Neo-Liberal paradigm, working class children run the risk of remaining in the margins of society. Modern day bureaucracies are victims of the performance culture that is promoted by the World Bank other supra national organisations.

\section{What are developing countries?}

Developing nations are those with low, lower middle or upper middle incomes. Common characteristics of developing countries are low levels of living characterized by low income, inequality, poor health and inadequate education. -a general sense of malaise and hopelessness. 
Developing countries are poor. By definition, GDP and Per Capita Income are at low level. General living standard of people in these countries is very slow. Poverty is visibly disturbing every aspect of life. General health services for people is insignificant. The life expectancy at birth does not exceeds 60 years. As a result the living standard of the people of such countries is also very low. People have difficulty in consuming even daily necessity. South Africa's average salary data is skewed by large levels of inequality, and excludes the large informal sector. For example, domestic workers, of which there are over 1 million employed in South Africa, earn approximately R2,500 per month - this equates to just over $\$ 5,160$ per year. StatsSA's (2017) latest data also shows that South Africa has more domestic workers in employment than it does professionals, currently making up $6.2 \%$ of the country's 16.2 million person workforce. Professional make up 5.5\%, with the gap between the two groups widening every quarter. South Africa also has an incredibly high unemployment rate, with $27.7 \%$ of workers out of a job - and by the broader definition putting it over $36 \%$.

We have largely followed developed models of education which have a totally different pupil composition. Planning for the poor and working class can be done effectively if we use the concept inclusive education as a framework of thinking and practice. The underlying principal of inclusive education is to examine what barriers exist in the system that prevent learners from learning and address those barriers in planning rather than psychologizing failure. There is scope in education during the formative years to take into consideration different intelligences that learners possess. In the current system anyone who fails is regarded as having deficiencies. The argument of inclusive education is what barriers exist in the system that prevents success and each of these barriers requires an assessment in order to create the conditions for learners to learn.

The main thrust of this paper is that developing countries should embrace an inclusive ideology that results in radical changes to theory, assumptions, models and practices. Developing countries have not brought the marginalised and alienated to the centre of the education system. The point 
is that they should examine every barrier to learning and find solutions for that, for example, disaggregate the various effects of poverty, establish how language can be an impediment to learning, develop responses to poorly educated parents and curriculum development should be contextualized within the specificities of countries. There should be a clear understanding how the history of special education has psychologized failure and influenced the thinking of mainstream bureaucrats and educationists. Vulnerable children remain in the margins and will continue to occupy positions in the margins of society in the developing world.

Inclusive education must be accompanied by structural change and programmatic changes. This type of transformation will assist in embracing large numbers of children that are alienated from the mainstream as a result of socio-economic challenges and challenges related to the performance culture that is driven by the World Bank, OECD and other supra national organisations. The performative culture encouraged by these organisations create the conditions for instability, violence and a conflict ridden societies. Too many children in developing countries become part of high attrition and perform poorly in literacy and numeracy because the focus is on top performers. To build better and more stable societies we need to develop a nurturing supportive culture in education instead of our obsession with performance. We cannot compare ourselves with other countries in the Western world. In those countries children in the margins are experiencing great difficulty in school and often are placed in special education facilities. Unfortunately, in developing countries there is a substantial number of children who are sitting in the margins. Ideas from the World Bank and related organisations do not hold in developing nations. We need to develop a safety net for children since this is not possible in many of their homes. For example, children who constitute the other are overrepresented in special education in the UK and many accuse the United States education system of creating schools as a pipeline to prison. 
My sense is that developing countries should examine their contexts and find ways to keep children in school so that they do not become victims of neo-liberalism. That responses should be found for children to succeed in reading and writing, especially, in the formative years so that conditions are created for children to graduate from school. We know that if children do not learn to read by the age of 6 they are unlikely to complete schooling. When developing nations opt for a performative culture they tend to take care of the top performers and the more privileged learners in the schooling system. The weak and vulnerable will be lost and never find a place in mainstream economic and social life. We have to develop a safety net for vulnerable children in the formative years Grade $\mathrm{R}$ to Grade 4.

\section{Now what is an inclusive ideology and what are the assumptions, models and tools that are associated with this practice?}

Inclusion is a term that emerged in the late $1950 \mathrm{~s}$ in response to criticisms of segregated institutions by disabled people, which resulted in separation of disabled children from their family, peers and local communities (Hodgkinson, 2016). However, we are not only talking about disabled learners here, we are referring to all learners, particularly those who are working class and find it difficult to interact with a middle class curriculum. The disability movement as a political movement aided by a growth of the disability studies to aid this movement, led to a subsequent shift in thinking from a medical model of viewing impairment as the only cause of educational difficulties to a social model of examining social processes and factors which result in difficulties (Norwich, 2013). The focus is on addressing cultural, ideological and material forces, which generate and legitimate policies and practices on exclusion for all learners (Armstrong et al, 2000). The shift is away from categorizing and pathologising some learners, for example those with socio-economic challenges, as being the 'other' and to focusing on all forms of marginalization and exclusion based on gender, ethnicity, cultural background, sexuality, and physical, cultural and material recourses (Nind et al, 2003). Inclusive education therefore calls for 'restorative practice', 
school transformation and renovation to address exclusion and not simply moving children into unchanged institutions (Slee, 2011)

If we apply the notion of inclusion to learners who struggle in the mainstream we can revolutionise our schooling systems. We know that learners who do not experience success in the mainstream find their lack of success psychologized. Instead every developing country should examine all the barriers in the system that make it difficult for learners to succeed.

\section{The Case of South Africa}

South Africa is a developing country with huge disparities derived from the apartheid dispensation. Many people do not have adequate educational qualifications and relevant skills, unemployment is very high and large numbers live in poverty. In order to contribute to breaking the cycle of disadvantage, there is a need to ensure that all children receive a quality education from a very early age. Impoverished families are generally unable to provide adequate resources at home for their children to achieve school readiness. Poverty, combined with parents' low level of education, contributes to learner underachievement. One of the White Papers launched in South Africa was Education White Paper 6 on Special Needs Education: Building an Inclusive Education and Training System. However, this paper was not implemented at a structural and programmatic level leaving many poor learners in the same situation they were when arriving at school on the first day. Planning and development of the inclusive system should bring the vulnerable child to the centre of the system and planning should take place accordingly.

The Western Cape has been selected as a suitable example in this discussion since it is the second richest province. A closer look at the education profile in the Western Cape, the second wealthiest province in South Africa, provides a bleak picture. According to the Human Capital Strategy (2007:10) developed by the provincial Department of Education, only $23.4 \%$ of the population of learners in the Western Cape complete grade 12. Over a third (36.5\%) drop out during the secondary school phase; a small proportion complete primary education (7.9\%). Fifteen percent 
(15.2\%) of the latter figure drop out during the primary phase. Five (5.7\%) of the total learner population have no schooling at all. Enrolment and completion of schooling by the age of 17 years is highest amongst white learners (100\%); the enrolment and completion rate is lower amongst the African population; and lowest amongst coloured learners. For those learners currently at school, only $37 \%$ of learners at grade 3 level achieve grade-appropriate literacy and numeracy levels. At grade 6 level, numeracy performance drops to $15 \%$, and literacy performance to $35 \%$. These statistics are alarming if we consider that the education sector receives $38.1 \%$ of the total provincial budget (Human Capital Development Strategy 2007:10).

Against the backdrop of the apartheid legacy, it is evident that the most disadvantaged learners are black and thus experience the least success in the education system. Yet, after fifteen years of funding education on a pro-poor basis with the emphasis on equity, it seems very little has been achieved. According to the OECD (2008:53) three international learning assessments of the outcomes of South African schooling: the Monitoring Learning Achievement (MLA) project conducted in 1999, Trends in International Mathematics and Science Study (TIMMS) conducted in 1995, 1999 and 2003 and the Southern Eastern African Consortium for Monitoring Educational Quality (SAQMEC) completed in 1991 confirm that South Africans are performing poorly and the education system is not delivering quality education. The high dropout rate and the low pass rates in literacy and numeracy suggest that much still has to be done. A guiding principle of the National Curriculum Statement for South African schools is social justice. (DOE:2002) Both literacy and numeracy are social justice issues, as a lack of literacy and numeracy excludes one from mainstream economic and social life (Bearne \& Marsh 2007). Teaching young children literacy and numeracy through ECD establishes a sound base for learning and is an important strategy to reach the goal of social justice. The socio-economic conditions in families determine to a large extent the quality of learning environment at home. Statistics that focus on the Western Cape illustrate this point. According to the Provincial Economic 
Review and Outlook research in 2007 ( this is the full reference) (2007:5), $25.5 \%$ of people in the Western Cape are unemployed. A further analysis of the data indicates the following:

- Between the ages of 15 and 24, 49.1\% are unemployed.

- Between the ages of 25 and 34, 23.7\% are unemployed.

- Between the ages of 35 and 44, 18.1\% are unemployed.

- Between the ages of 45 and 54, $13.1 \%$ are unemployed.

Thus, a large percentage of younger parents who are likely to have young children are unemployed. These homes have limited educational resources and lack a print culture, and early literacy is minimal. This implies few books, little interest in school work and a lack of a reading and oral language culture.

Changing from a dual system of education (special and ordinary) to an inclusive system of education requires substantial change in terms of thinking and practices. After twenty years of implementing Education White Paper 6 (DOE, 2001), it is very important that theories, assumptions, practices, models and tools are put under immense scrutiny for the inclusive policy to work. The single system of education should develop the capacity to address barriers to learning if it wants to include all learners into the education system. What are the main barriers that deprive learner's access to a single system of education and what changes should take place so that a truly inclusive system can be created? South Africa introduced 7 white papers in education but they were all implemented in ways that was not entirely influenced by the theory and practice of inclusive education. Inclusive education requires of the system to change at a structural level so that the mainstream of education takes ownership of the ideology and practice of inclusive education. This should bring about consistency in relation to other white papers, for example, curriculum development, early childhood education, adult education and other areas of education. This paper suggests that in implementing inclusive education South Africa did not take seriously the various barriers, such as the curriculum in providing access to learners who experience barriers. 
The social portrait of South Africa based on its second richest city suggests that a substantial part of the pupil population could benefit from an inclusive education system. Too many learners in country remain in the margins of society as a result of historical factors such race and class. To bring people to the centre, an inclusive education system that addresses the theory and practice of change is imperative. What follows are a few ideas on the way forward.

Firstly, education departments need to investigate their organograms with a view to providing an effective inclusive service. Whilst some provinces have made progress in this regard, the national Department of Basic Education and some provinces will probably find that they have to change their structures in order to make inclusive education work. There is no point in talking about an inclusive education system when old special education units are entrusted with the transformation to an inclusive education system. It's like saying racist people should transform the society into a non- racial one. The structures of the department should take ownership of inclusion by developing programmes that includes all learners including curriculum, learner transport, learner and teacher support materials.

Secondly, there should be a thorough examination of all barriers which include socio-economic factors, teacher limitations, curriculum, language, transport, parent challenges and so on. The education department should not shift the responsibility of challenging learners to a section that sits outside the mainstream of education.

Thirdly, it is quite apparent that apartheid education had firmly establishes structures for mainstream education and special education which included separate personnel, curricula and facilities. Anyone who deviated from the norm was regarded as the other in the schooling system. Victim blaming and the psychologization of school failure was a central feature of education during the apartheid era and special education. Schools and the curriculum was used as the primary means of reproducing the status quo. The medical model was the dominant model and the focus of the cause of most learning challenges were located within the learner. The entire focus 
was on the individual who was viewed as helpless and dependent. The individual deficit theory (medical model) viewed the person as in need of treatment and assistance outside regular education. In conclusion it is critical that all barriers to learning become the core of planning and interrogation to create space and possibilities for access. This is including the following barriers: Language, Negative Attitudes, Socio-economic factors, Parental attitude, Lack of appropriate and clear policy, Access to the curriculum, an Lack of access to a print culture. 